Research Article

\title{
Temperature and Stress Effects on the Compressive Creep Behavior of Parallel Strand Bamboo
}

\author{
Yanyan Liu $\mathbb{D},{ }^{1}$ Yulin Bian, ${ }^{2}$ Dong He, ${ }^{3}$ Jiao Liu, ${ }^{1}$ and Aiping Zhou $\mathbb{D}^{1}$ \\ ${ }^{1}$ National Engineering Research Center of Biomaterials, Nanjing Forestry University, No. 159 Longpan Road, Nanjing 210037, \\ Jiangsu, China \\ ${ }^{2}$ Wuxi Vocational Institute of Commerce, No. 809 Qianhu Road, Wuxi 214153, Jiangsu, China \\ ${ }^{3}$ Dongfang Tubine Co., Ltd., No. 666 Jinshajiang Road, Deyang 618000, Sichuan, China \\ Correspondence should be addressed to Yanyan Liu; liuyanyan@njfu.edu.cn
}

Received 25 November 2020; Accepted 25 May 2021; Published 4 June 2021

Academic Editor: Quoc-Bao Bu

Copyright (C) 2021 Yanyan Liu et al. This is an open access article distributed under the Creative Commons Attribution License, which permits unrestricted use, distribution, and reproduction in any medium, provided the original work is properly cited.

\begin{abstract}
Parallel strand bamboo (PSB) is an engineered bamboo product fabricated using crushed bamboo fiber bundles. Recently, this product finds applications in the civil engineering field. It is expected that the use of this composite will continue to grow because of its excellent mechanical performance, relatively low variability in material properties, and shape standardization. Modern bamboo structures made from PSB composites may be subjected to temperature variations during service. So far, however, there has been little discussion about the temperature-dependent creep. In this study, an investigation was carried out on the short-term behavior of the compressive property of PSB. A stress range of 8 to $64 \mathrm{MPa}$ over a temperature range of $25^{\circ} \mathrm{C}$ to $75^{\circ} \mathrm{C}$ was considered in the 24-hour creep tests. In addition, Burgers model was adopted to describe the short-term creep behavior of PSB. Temperature and stress effects on the creep compliance of the Burgers model were also discussed.
\end{abstract}

\section{Introduction}

Parallel strand bamboo (PSB), a kind of engineered bamboo product, is made from raw bamboo strands which are compressed along the grain direction under high pressure. It has been proved that PSB has excellent mechanical properties and is an important alternative to traditional constructional materials [1-4]. This engineered bamboo product is considered to have great potential to be used as structural columns, beams, and flooring materials in the construction industry [5-8]. Biomaterials, such as wood and bamboo, are classified as viscoelastic materials at normal operating load, temperature, and moisture content. The viscoelastic behavior-induced microvoids and microcracking may lead to stiffness degradation and consequently develop macrocracks resulting in the premature failure of structures, of which the stress is significantly lower than expected. To avoid the creep rupture of a structural member, design codes require reductions in static strength to account for long-term performance. Therefore, it is necessary to evaluate the creep and relaxation of biomaterials since this property may affect their long-term performance.

More recently, a considerable amount of literature has been published, including mechanical properties of PSB, fracture toughness, fire resistance, and performance of PSB columns/beams [7-14]. However, few writers have been able to draw on any systematic research into the viscoelastic properties of PSB. To the authors' knowledge, no single study exists which discusses the variation of tensile/compressive properties of PSB during a wider temperature range and a time duration. Modern bamboo structures made from PSB may be subjected to temperature variations during service. For instance, on winter nights, the temperature on the surface of some structural members can reach below $0^{\circ} \mathrm{C}$. In a hot climate under direct sun, however, the temperature can even rise to over $50^{\circ} \mathrm{C}$ [15]. Hence, characterization of PSB creep behavior under a wide temperature range is important to ensure confidence in structure design and to assess potential failure due to excessive deformation or rupture. 
Over the past few decades, there have been several investigations into the creep behavior of wood and wood-based composites. 10-hour creep tests of SPF under constant temperature and humidity were performed by Kuwamura [16]. He states that when the stress level exceeds $80 \%$ of the static strength, the creep strain transitions from the secondary stage to the tertiary stage and terminates in fracture. Kobbe et al. [17-21] conducted short- and long-term creep tests on wood-based composites to evaluate the creep behavior and concluded that they are very sensitive to the magnitude of the applied load, temperature, and relative humidity changes. The overall effect of temperature was an acceleration of creep with increasing temperature. In recent times, several investigations were devoted to creep behavior of raw bamboo material [22-24]. The effects of the environmental condition and the specimen part (outer or inner culm of the bamboo stem) have been clarified. $\mathrm{Wu}$ [25] conducted tensile and compressive creep tests of PSB at a stress range between $10 \%$ and $40 \%$ of tensile/compressive strength under constant temperature and relative humidity. The material exhibited linear viscoelastic behavior within the applied stress levels.

The time-dependent behavior of PSB, however, is not well understood at elevated temperatures, and very little information is available. The present study sets out to assess the temperature effect on the creep behavior of PSB composites. The creep tests over a stress range of $8 \mathrm{MPa}$ to $32 \mathrm{MPa}$ and a temperature range of $25^{\circ}$ to $75^{\circ} \mathrm{C}$ were conducted in a temperature-controlled environmental chamber. The relative humidity was set at 50\%. The results and analysis from creep tests were reported in detail. Moreover, the Burgers model was adopted to evaluate the creep behavior, and the creep compliance of the Burgers model was discussed.

\section{Experimental}

2.1. Material and Manufacturing. The experimental material used in this study was manufactured using 5-year-old Moso bamboo from the Jiangxi province of China. Firstly, bamboo culms were split into strips which are $2 \mathrm{~m}$ long with a section of $15 \mathrm{~mm}$ in width and $3 \mathrm{~mm}$ in thickness. The bamboo strips were carbonized for $140 \mathrm{~min}$. The temperature and pressure were $130^{\circ} \mathrm{C}$ and $0.3 \mathrm{MPa}$, respectively. Carbonation treatment can improve the weatherability and dimensional stability of the PSB product and reduce shrinkage and swelling deformation. The bamboo strips were then dried at $80^{\circ} \mathrm{C}$ temperature until they reached a moisture content of approximately $11 \%$. After carbonizing and drying treatment, the strips were crushed into rough bamboo strands. The strands were then impregnated with water-soluble phenolic resin. The solid content of resin and the impregnation time were $25 \%$ and $14 \mathrm{~min}$, respectively. Then, the strands were compressed under a pressure of $4 \mathrm{MPa}$ at $160^{\circ} \mathrm{C}$ to make PSB panels. The curing time is related to the thickness of the PSB panel, generally $1 \mathrm{~min} / \mathrm{mm}$.

2.2. Creep Test Procedure. All the specimens used in this study were designed per ASTM D2990-17 [26]. As shown in
Figure 1, the manufactured PSB panels were cut into specimens of $100 \mathrm{~mm}$ length with a section of $25 \mathrm{~mm} \times 25 \mathrm{~mm}$.

Creep tests are very sensitive. Thus, applying constant load and no shock during the creep test are expected. The creep tests were conducted in a temperature-controlled environmental chamber controlled to $50 \%$ relative humidity. Three temperature levels of $25^{\circ} \mathrm{C}, 50^{\circ} \mathrm{C}$, and $75^{\circ} \mathrm{C}$ and three stress levels of $8 \mathrm{MPa}, 16 \mathrm{MPa}$, and $32 \mathrm{MPa}$ were selected. Initially, the stress level of $64 \mathrm{MPa}$ was also selected. However, the specimens at the stress level of $64 \mathrm{MPa}$ and the temperature of $50^{\circ} \mathrm{C}$ and $75^{\circ} \mathrm{C}$ failed prematurely. Only at $25^{\circ} \mathrm{C}$, strain data under the stress of $64 \mathrm{MPa}$ were recorded during the whole creep test. Thus, we also reported the results of $64 \mathrm{MPa}$ in Section 3.1. Specimen temperatures during the creep tests were maintained within a tolerance of $\pm 1^{\circ} \mathrm{C}$ to the target temperature. The average value of the ultimate static strength of PSB is $106.7 \mathrm{MPa}$ at $25^{\circ} \mathrm{C}$ and drops to $42.7 \mathrm{MPa}$ at $75^{\circ} \mathrm{C}$. Hence, the lowest stress level $8 \mathrm{MPa}$ was about $7.5 \%$ of the compressive strength at $25^{\circ} \mathrm{C}$ and $18.7 \%$ of that at $75^{\circ} \mathrm{C}$. The highest stress level $32 \mathrm{MPa}$ was about $30 \%$ of the compressive strength at $25^{\circ} \mathrm{C}$ and $74.9 \%$ of that at $75^{\circ} \mathrm{C}$. All the specimens were preconditioned for the target temperature. Each creep test lasted 24 hours. The load, deformation, and time were recorded immediately following loading and at an interval of $15 \mathrm{~s}$ in the first hour and then at an interval of $75 \mathrm{~s}$ for the next 23 hours. The test setup and environmental chamber arrangement are shown in Figure 2(a), whereas the schematic representation is shown in Figure 2(b).

Since scatter in the properties is unavoidable in PSB, creep tests set at each test condition were repeated three times to improve the confidence of the test results. These specimens were named "Temperature-stress-No." For example, the specimens tested at $25^{\circ} \mathrm{C}$ and $8 \mathrm{MPa}$ were named “ $25^{\circ} \mathrm{C}-8 \mathrm{MPa}-1 / 2 / 3$." The average results using three separate specimens were adopted for discussion.

\section{Results and Discussion}

3.1. Creep Behavior at Room Temperature. The time-dependent behavior of PSB specimens at $25^{\circ} \mathrm{C}$ and different stress levels is displayed in Figure 3. All the specimens showed similar behavior, and no creep rupture was observed.

The specimens first suffered an instantaneous strain upon loading. The instantaneous strain was expected to be more pronounced for greater loading. Such behavior can be seen in Figure 3. The strain then increased over time. This time-dependent response is creep strain. Creep behavior of wood composites is generally considered to have three stages $[27,28]$. As shown in Figure 4, they are primary, secondary, and tertiary stages. Generally, primary creep occurs in a relatively short period of time. During the primary stage, the strain usually increases with a continuously decreasing strain rate. Then, the secondary creep stage with a constant strain rate is usually reached. The duration of the secondary stage is related to material properties, the level of sustained loading, and the loading condition. The tertiary stage usually indicates progressive failure of the material. It is clear that, at the 


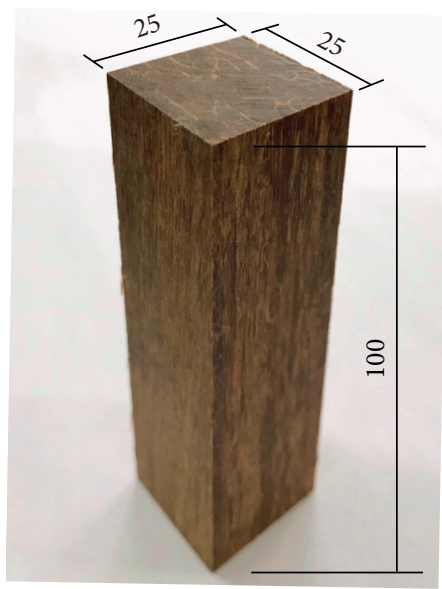

FIGURE 1: PSB specimen for the compressive creep test (unit: $\mathrm{mm}$ ).

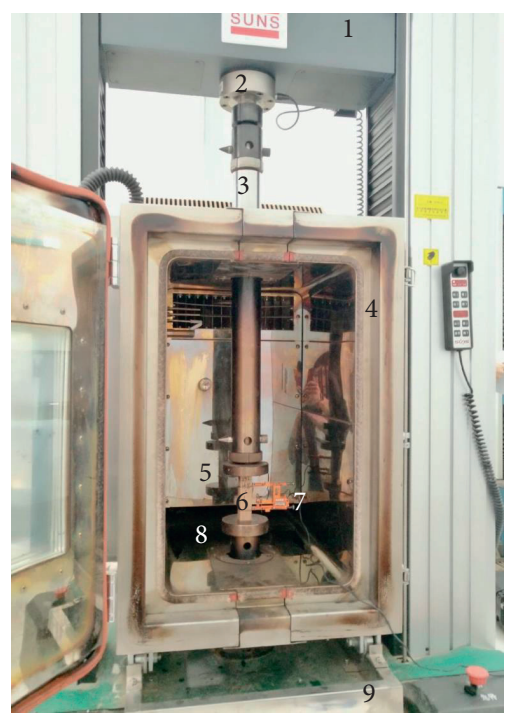

(a)

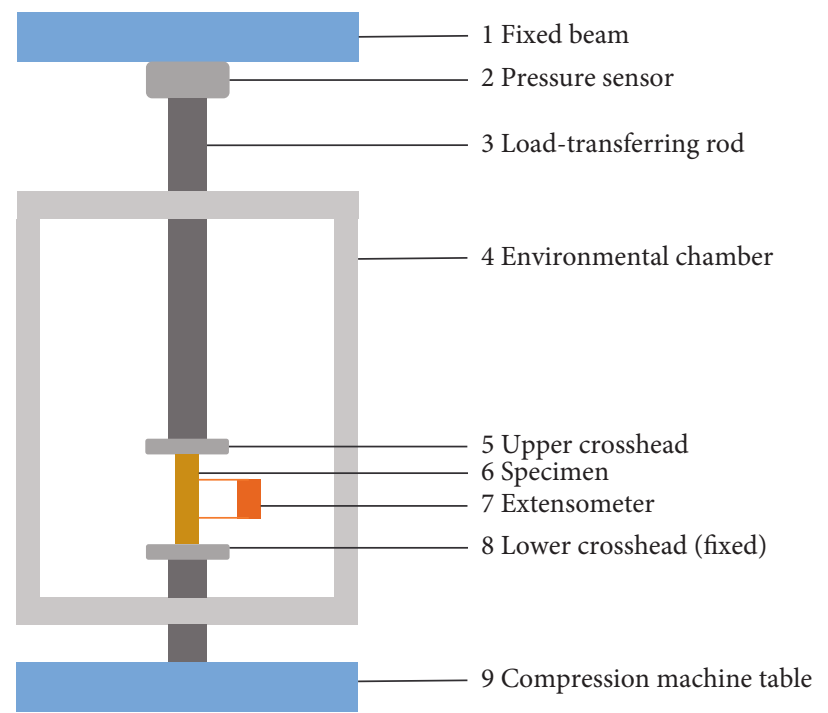

(b)

FIgURe 2: Experimental setup used in this study. (a) Test setup for loading. (b) Schematic of the test setup.

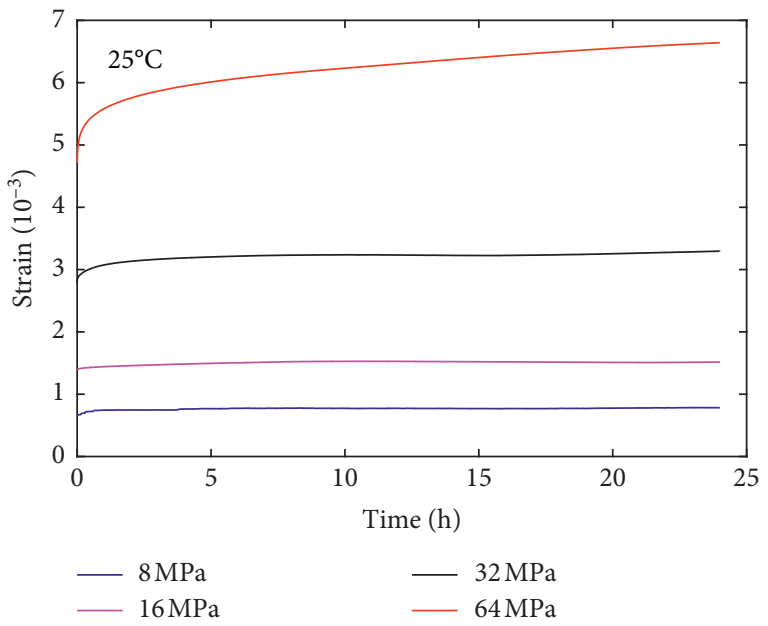

Figure 3: Creep behavior of PSB at $25^{\circ} \mathrm{C}$ and different stress levels. 


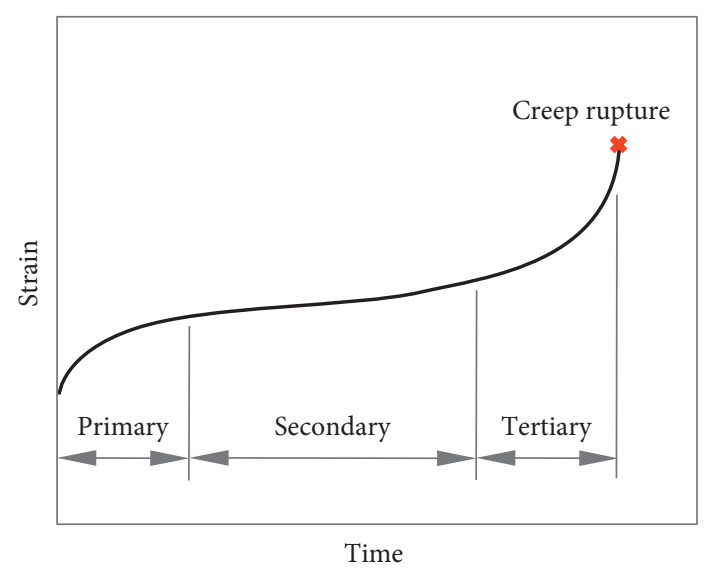

FIgURE 4: Three stages of the creep curve.

end of the tests, all specimens stay in the secondary creep stage.

The creep responses in the range of $8-64 \mathrm{MPa}$ at $25^{\circ} \mathrm{C}$ are similar such that creep strains increase over time. As shown in Figure 3, the stress levels had an influence on the amount of creep strain of PSB material. The higher the level of sustained loading, the larger the creep strain. From the figure, we can see that, at the end of the tests, the creep strain was $0.79 \times 10^{-3}$ under the stress level of $8 \mathrm{MPa}$. The creep strain increased to $3.30 \times 10^{-3}$ at the stress level of $32 \mathrm{MPa}$ and further increased to $6.64 \times 10^{-3}$ at the stress level of $64 \mathrm{MPa}$. These results suggest that, at the temperature of $25^{\circ} \mathrm{C}$, the increase in creep strain was proportional to the increase in stress within the range of this study.

When observing the creep curves plotted in Figure 3, note that the strain rate at $64 \mathrm{MPa}$ is higher than the lower stress level. The observed difference may indicate the existence of a change in the creep mechanism at the high stress level. At lower stress levels, the creep is mainly induced by the molecular motions, while at higher stress levels, the creep may be dominated by the damage that occurred in the material.

3.2. Creep Behavior at Elevated Temperature. Considering the variation of seasonal temperatures in the south area of China, temperature variations at the surface of structural members are estimated to range from $25^{\circ} \mathrm{C}$ to $75^{\circ} \mathrm{C}$.

Figure 5 may help us understand the temperature effect on creep behavior. At a constant stress level, the creep strain increased with the temperature. A possible explanation for this might be that exposure to high temperatures reduces the stiffness of PSB material [11]. At the stress levels of $8 \mathrm{MPa}$ and $16 \mathrm{MPa}$, the creep strain at the end of the test was increased 2 times when the temperature was increased from 25 to $75^{\circ} \mathrm{C}$. In the creep test under $75^{\circ} \mathrm{C}$ with the sustained load of $32 \mathrm{MPa}$, two specimens $\left(75^{\circ} \mathrm{C}-32 \mathrm{MPa}-1\right.$ and $75^{\circ} \mathrm{C}$ $32 \mathrm{MPa}-3)$ failed within 24 hours. Therefore, the creep curve of $75^{\circ} \mathrm{C}$ in Figure 5(c) is not the average result, but the result of specimen $75^{\circ} \mathrm{C}-32 \mathrm{MPa}-2$.
It can be seen from Figures 3 and 5 that the temperature and stress level have a great influence on the amount of creep strain of PSB material. However, the strain rate appeared to be unaffected by the temperature and stress levels, except for the case with the stress of $32 \mathrm{MPa}$ and temperature of $75^{\circ} \mathrm{C}$.

Although this study was not intended to investigate the creep rupture of PSB material, specimen failure was recorded at the stress level of $32 \mathrm{MPa}$. As shown in Figure 6, the specimens enter the tertiary stage when the load is maintained for 17-18 hours. The creep deformation increases sharply, leading to creep rupture, indicating the likelihood of some material damage resulting from the increased temperature and sustained loading in this case. Such results suggest that although the bamboo-based structure is designed at low stress levels, high temperature and long time may still cause large creep deformation and even material failure.

\section{Modeling of Creep}

4.1. Burgers Model. To evaluate the time-dependent behavior of PSB material, a reliable and widely accepted model is needed. The generalized Kelvin model has been proven to apply to a variety of viscoelastic materials $[29,30]$. Since this study focuses on the short-term creep behavior, the Burgers model which can be seen as a simple generalized Kelvin model consisting of one Kelvin unit is adopted here.

The Burgers model consisting of a Maxwell unit and a Kelvin unit in series is reasonably simple, as shown in Figure 7(a). Considering a creep test of a PSB specimen under compression, the behavior of the Burgers model can be understood as the combination of the element behavior connected in series in Figure 7(a). Thus, the total strain of the Burgers model at time $t$ is decomposed into three parts:

$$
\varepsilon(t)=\varepsilon_{1}(t)+\varepsilon_{2}(t)+\varepsilon_{3}(t)
$$

where $\varepsilon_{1}, \varepsilon_{2}$, and $\varepsilon_{3}$ are the strain of the spring, Newton's dashpot, and the Kelvin unit, respectively. Given the stiffness and viscosity of the elements in the Burgers model, $\varepsilon_{1}, \varepsilon_{2}$, and $\varepsilon_{3}$ can be expressed as 


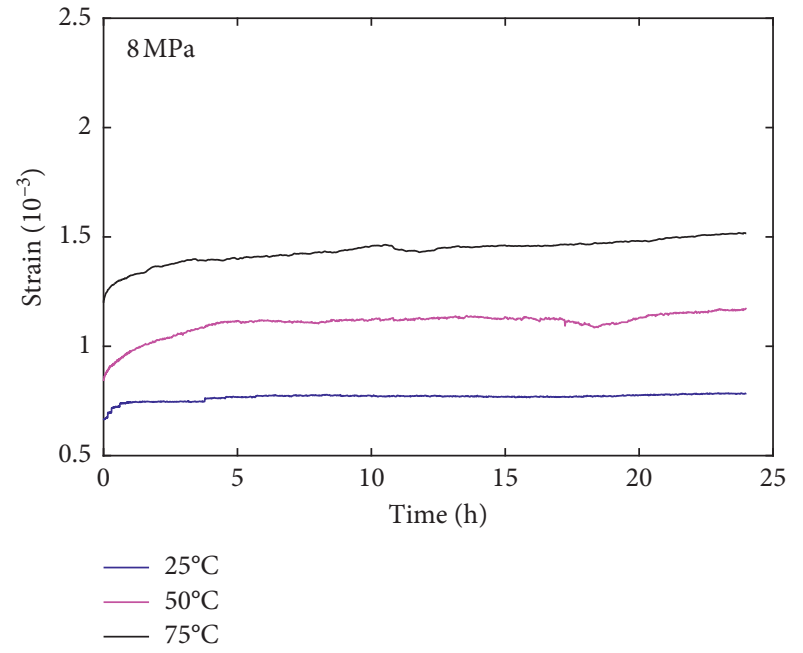

(a)

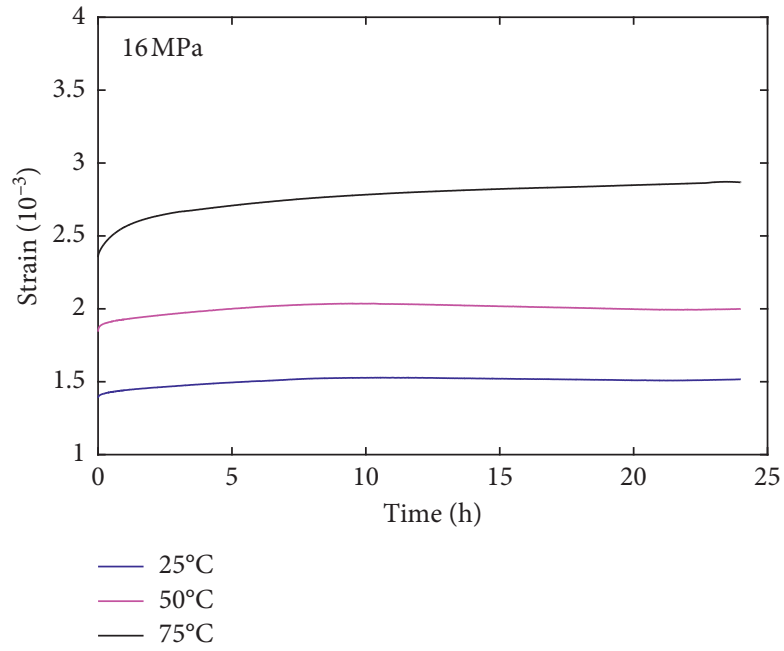

(b)

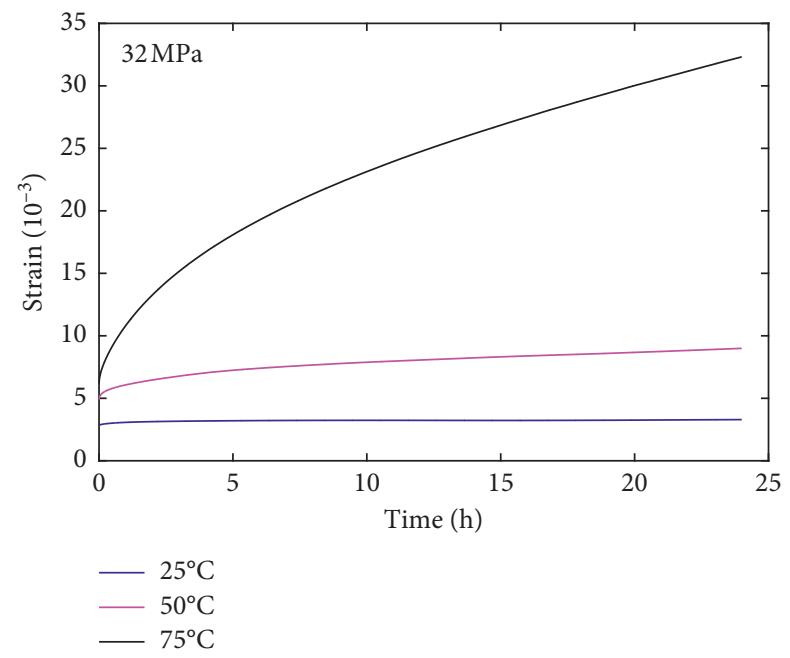

(c)

Figure 5: Creep behavior of PSB at temperatures between 25 and $75^{\circ} \mathrm{C}$. (a) Creep test results at constant loading of $8 \mathrm{MPa}$. (b) Creep test results at constant loading of $16 \mathrm{MPa}$. (c) Creep test results at constant loading of $32 \mathrm{MPa}$.

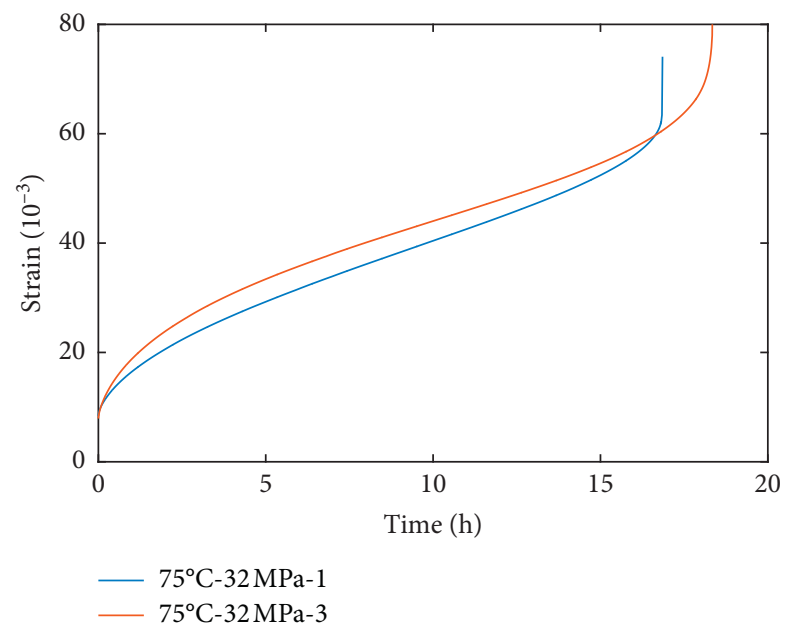

Figure 6: Creep rupture of specimens at $75^{\circ} \mathrm{C}$ and $32 \mathrm{MPa}$. 


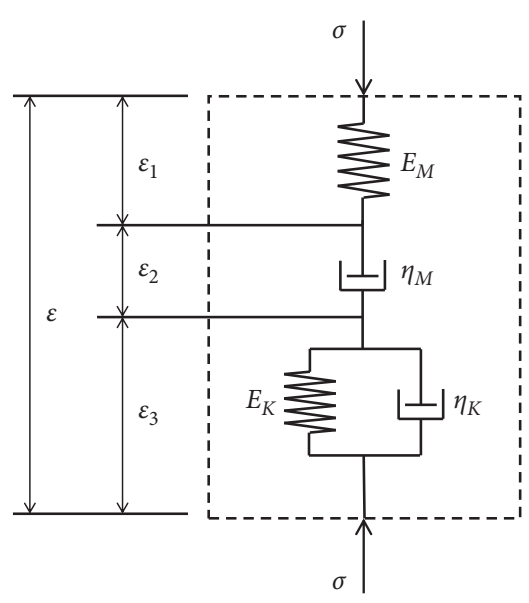

(a)

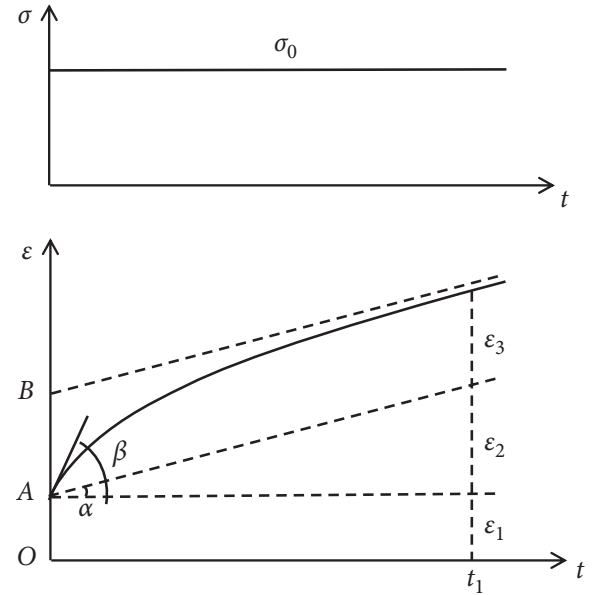

(b)

Figure 7: Burgers model. (a) Schematic illustration. (b) Creep response under a constant load.

$$
\begin{array}{r}
\varepsilon_{1}=\frac{\sigma}{E_{M}}, \\
\dot{\varepsilon}_{2}=\frac{\sigma}{\eta_{M}}, \\
\dot{\varepsilon}_{3}+\frac{E_{K}}{\eta_{K}} \varepsilon_{3}=\frac{\sigma}{\eta_{K}},
\end{array}
$$

where $E_{M}$ and $\eta_{M}$ are the stiffness and viscosity of the Maxwell unit, respectively, and $E_{K}$ and $\eta_{K}$ are the stiffness and viscosity of the Kelvin unit, respectively.

The creep response of the Maxwell model is the sum of the spring and Newton's dashpot:

$$
\varepsilon_{1}(t)+\varepsilon_{2}(t)=\frac{\sigma}{E_{M}}+\frac{\sigma}{\eta_{M}} t
$$

On the right-hand side of (5), the first term represents the instantaneous elastic strain since the spring will act immediately upon loading. The second term represents viscous flow because it takes time for the dashpot to build up the strain.

The creep behavior of the Kelvin model is expressed by solving first-order nonhomogeneous ordinary differential equation (4) with the initial condition $\varepsilon_{3}(0)=0$. Thus,

$$
\varepsilon_{3}(t)=\frac{\sigma}{E_{K}}\left(1-e^{-\left(E_{K} / \eta_{K}\right)^{t}}\right) \text {. }
$$

The right-hand term of (6) represents delayed elasticity of the Kelvin model. Then, the creep strain of the Burgers model can be expressed as follows:

$$
\varepsilon(t)=\frac{\sigma}{E_{M}}+\frac{\sigma}{\eta_{M}} t+\frac{\sigma}{E_{K}}\left(1-e^{-\left(E_{K} / \eta_{K}\right)^{t}}\right) .
$$

Differentiating (7) yields the creep rate $\dot{\varepsilon}$ :

$$
\dot{\varepsilon}(t)=\frac{\sigma}{\eta_{M}}+\frac{\sigma}{\eta_{K}} e^{-\left(E_{K} / \eta_{K}\right)^{t}} .
$$

Based on the knowledge of the physical response of simple elements in the Burgers model, the material constants $E_{M}, \eta_{M}, E_{K}$, and $\eta_{K}$ can be determined as follows:

$$
\begin{aligned}
\overline{O A} & =\frac{\sigma}{E_{M}}, \\
\tan \alpha & =\frac{\sigma}{\eta_{M}}, \\
\overline{A B} & =\frac{\sigma}{E_{K}}, \\
\tan \beta & =\frac{\sigma}{\eta_{M}}+\frac{\sigma}{\eta_{K}},
\end{aligned}
$$

where the four values $\overline{O A}, \overline{A B}, \alpha$, and $\beta$ illustrated in Figure $7(\mathrm{~b})$ are obtained from the creep curve.

Figure 8 compares the Burgers model with the creep test results. Both primary and secondary creep stages can be well represented by the Burgers model. The comparison demonstrates the effectiveness of this model to evaluate the short-term creep behavior of this material.

4.2. Creep Compliance. The creep response of Burgers model (7) may also be written in the form

$$
\varepsilon(t)=\sigma J(t)=\sigma\left(J_{0}+J_{\eta} t+J_{K}\left(1-e^{(-t) / \tau}\right)\right),
$$

and $J(t)$ is defined as the creep strain resulting from unit stress, known as the compliance function. It is the viscoelastic material property used to describe behavior during creep loading. $J_{0}$ is the initial compliance. It is time independent and only related to the elastic modulus of the spring in the Maxwell unit. $J_{\eta}$ is the delayed compliance due to the viscosity of the dashpot in the Maxwell unit. $J_{K}$ and $\tau$ are the delayed compliance and retardation time due to the Kelvin unit in the Burgers model. 


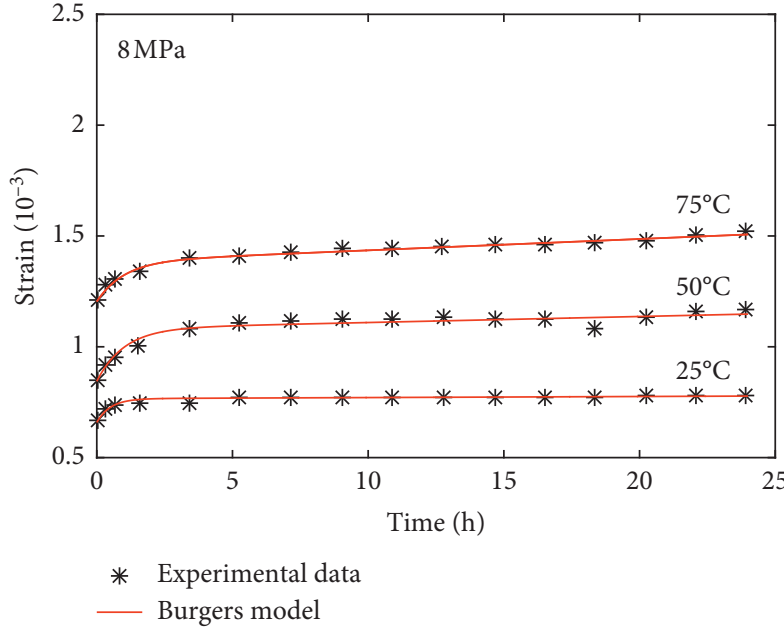

(a)

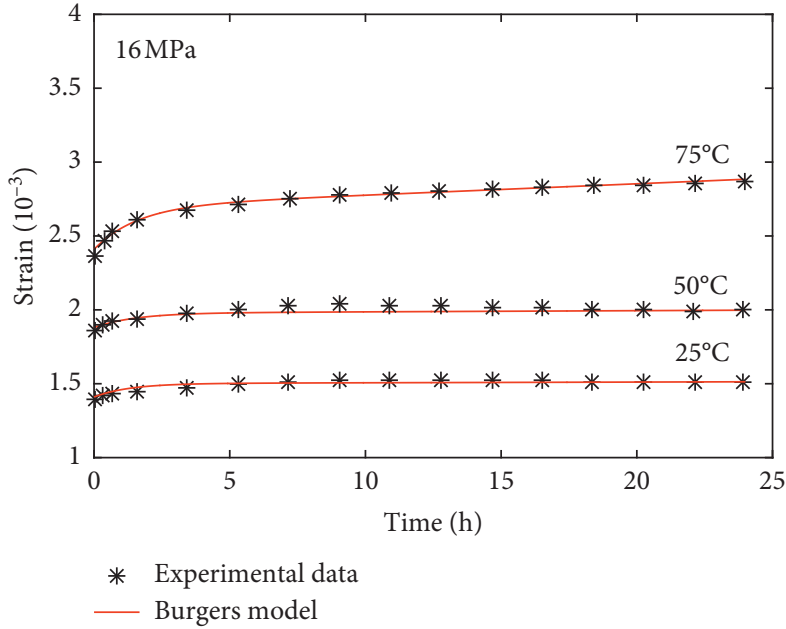

(b)

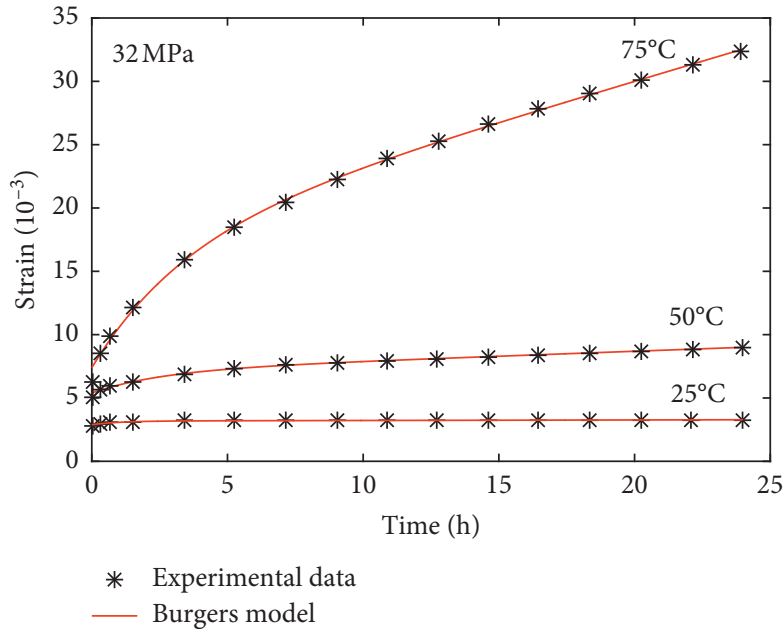

(c)

Figure 8: Measurements and Burgers model predictions for creep strain. (a) At constant loading of 8 MPa. (b) At constant loading of $16 \mathrm{MPa}$. (c) At constant loading of $32 \mathrm{MPa}$.

TABLE 1: Creep compliance and retardation time.

\begin{tabular}{lcccc}
\hline Condition & $J_{0}$ & $J_{\eta}$ & $J_{K}$ & \multicolumn{1}{c}{} \\
\hline $25^{\circ} \mathrm{C}-8 \mathrm{MPa}$ & 823.3 & 0.6 & 134.3 & 297.8 \\
$50^{\circ} \mathrm{C}-8 \mathrm{MPa}$ & 1055 & 3.4 & 224.9 & 1.0 \\
$75^{\circ} \mathrm{C}-8 \mathrm{MPa}$ & 1495 & 6.4 & 57.1 & 1.2 \\
$25^{\circ} \mathrm{C}-16 \mathrm{MPa}$ & 881.4 & 0.3 & 61.5 & 1.3 \\
$50^{\circ} \mathrm{C}-16 \mathrm{MPa}$ & 1175 & 0.5 & 181.2 & 1.5 \\
$75^{\circ} \mathrm{C}-16 \mathrm{MPa}$ & 1566 & 4.8 & 91.6 & 1.6 \\
$25^{\circ} \mathrm{C}-32 \mathrm{MPa}$ & 902.3 & 24.3 & 543.3 & 1.0 \\
$50^{\circ} \mathrm{C}-32 \mathrm{MPa}$ & 1686 & 198.2 & 3110 & 2.6 \\
$75^{\circ} \mathrm{C}-32 \mathrm{MPa}$ & 2307 & & 3.4 \\
\hline
\end{tabular}

The compliance $J_{0}, J_{\eta}, J_{K}$ and the time quantity $\tau$ are key characteristic properties of the model. Indeed, no knowledge of each element in the Burgers model is necessary. The creep response of a material can be completely characterized provided the creep compliance is known. The compliance can be derived from the data collected in the creep tests, as summarized in Table 1.
Figure 9 compares creep compliance values determined using different stress levels at elevated temperatures. Evaluating the compliance shows that compliance is temperature dependent. There is an increasing trend with temperature, especially at higher stress level. At a temperature of $25^{\circ} \mathrm{C}$, the compliance values are basically identical when the loads are no more than $32 \mathrm{MPa}, 30 \%$ of the static strength. This 


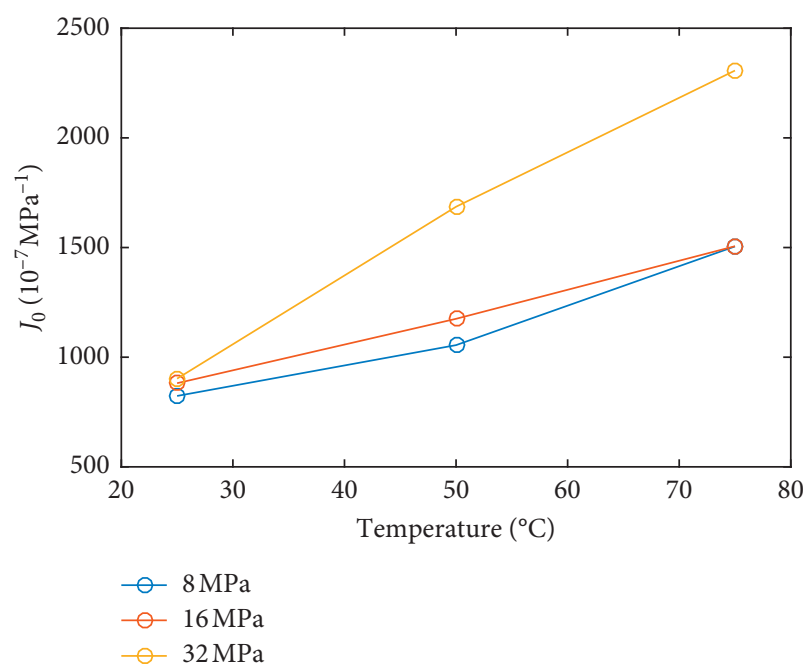

(a)

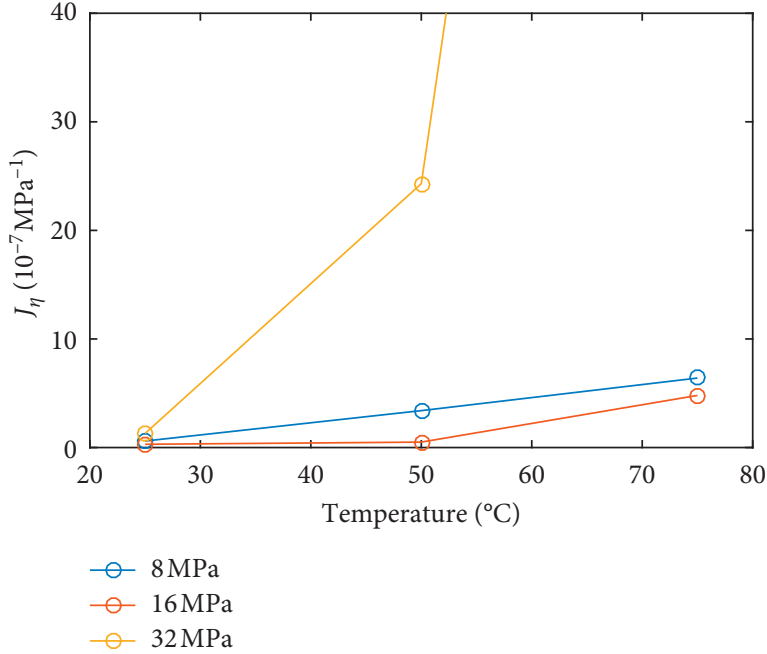

(b)

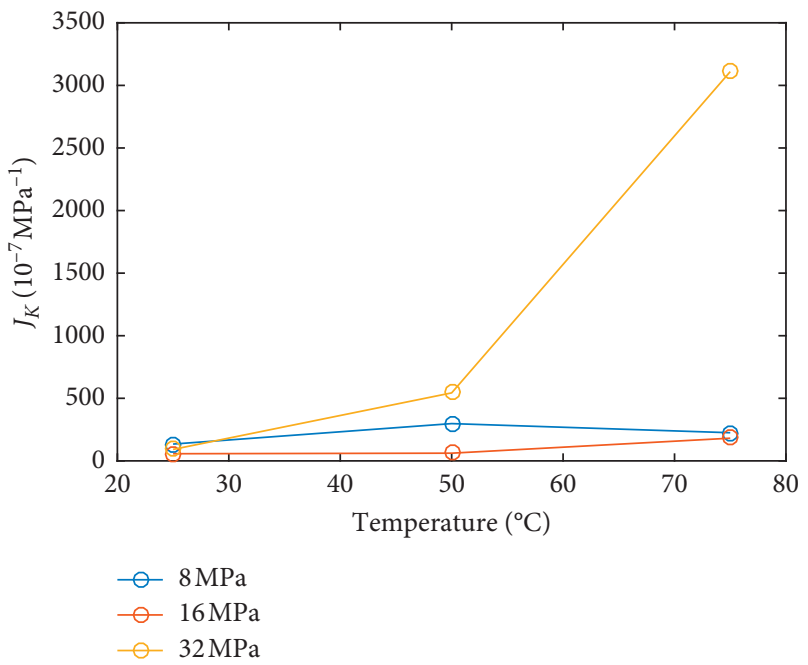

(c)

FIgURE 9: Evaluation of the creep compliance. (a) Initial compliance $J_{0}$. (b) Delayed compliance $J_{\eta}$. (c) Delayed compliance $J_{K}$.

indicates the linear viscoelastic behavior of PSB at relatively low temperature and under relatively low stress. High temperature and stress level may increase the creep compliance, leading to larger creep deformation.

\section{Conclusions}

The present study was designed to investigate the temperature and stress effect on the compressive creep behavior of PSB. The creep tests over a stress range of $8 \mathrm{MPa}-32 \mathrm{MPa}$ and a temperature range of $25^{\circ} \mathrm{C}-75^{\circ} \mathrm{C}$ were conducted in a temperature-controlled environmental chamber. At a constant load, the creep strain showed an increasing trend with the temperature. Elevated stress and temperature levels resulted in a noticeable higher creep rate, possibly indicating the existence of a different creep mechanism compared with relatively low stress and temperature conditions. Creep rupture observed in the creep test under $32 \mathrm{MPa}$ and $75^{\circ} \mathrm{C}$ demonstrates that although the bamboo-based structure is designed at low stress levels, high temperature and a long time may still cause large creep deformation and even material failure.

Burgers model has proven to be an effective model for short-term creep behavior of PSB material. Using the Burgers model, the primary and secondary creep stage was predicted with accuracies at all stress and temperature levels. The creep compliance of the Burgers model is basically identical at $25^{\circ} \mathrm{C}$ when the load is no more than $32 \mathrm{MPa}$, indicating the linear viscoelastic creep behavior of PSB at relatively low temperature and stress. High temperature and stress levels may increase the creep compliance, leading to larger creep deformation. While the Burgers model can be helpful in interpreting observed creep behavior, the model is only valid for conditions within the range of this study. In 
the future study, it is necessary to demonstrate the effectiveness of the model when used outside the conditions studied.

\section{Data Availability}

The data used to support the findings of this study are available from the corresponding author upon request.

\section{Conflicts of Interest}

The authors declare that they have no conflicts of interest.

\section{Acknowledgments}

The authors gratefully acknowledge the financial support provided by the National Natural Science Foundation of China (Grant nos. 51978338 and 52008212).

\section{References}

[1] X. Sun, M. He, and Z. Li, "Novel engineered wood and bamboo composites for structural applications: state-of-art of manufacturing technology and mechanical performance evaluation," Construction and Building Materials, vol. 249, Article ID 118751, 2020.

[2] C. Y. T. Ming, W. K. Jye, and H. A. I. Ahmad, "Mechanical properties of bamboo and bamboo composites: a review," Journal of Advanced Research in Materials Science, vol. 35, no. 1, pp. 7-26, 2017.

[3] A. Kumar, T. Vlach, L. Laiblova et al., "Engineered bamboo scrimber: influence of density on the mechanical and water absorption properties," Construction and Building Materials, vol. 127, pp. 815-827, 2016.

[4] D. Huang, Y. Bian, A. Zhou et al., "Experimental study on stress-strain relationships and failure mechanisms of parallel strand bamboo made from phyllostachys," Construction and Building Materials, vol. 77, pp. 130-138, 2015.

[5] B. Sharma, A. Gatoo, M. Bock et al., "Engineered bamboo: state of the art," Construction Materials, vol. 168, pp. 57-67, 2015.

[6] B. Sharma, A. Gatoo, M. Bock et al., "Engineered bamboo for structural applications," Construction and Building Materials, vol. 81, pp. 66-73, 2015.

[7] D. Huang, Y. Bian, D. Huang et al., "An ultimate-state-basedmodel for inelastic analysis of intermediate slenderness PSB columns under eccentrically compressive load," Construction and Building Materials, vol. 94, pp. 306-314, 2015.

[8] X. Wang, A. Zhou, and Y. H. Chui, "Load-carrying capacity of intermediately slender parallel strand bamboo columns with a rectangular cross section under biaxial eccentric compression," Bioresources, vol. 13, pp. 313-330, 2018.

[9] M. Xu, Z. Cui, Z. Chen et al., "The charring rate and charring depth of bamboo scrimber exposed to a standard fire," Fire and Materials, vol. 42, pp. 750-759, 2018.

[10] Y. Zhong, H. Ren, and Z. Jiang, "Effects of temperature on the compression strength parallel to the grain of bamboo scrimber," Materials, vol. 9, no. 6, Article ID 436, 2016.

[11] M. Xu, Z. Cui, Z. Chen et al., "Experimental study on compressive and tensile properties of a bamboo scrimber at elevated temperatures," Construction and Building Materials, vol. 151, pp. 732-741, 2017.
[12] F. K. Liew, S. Hamdan, M. R. Rahman, and M. Rusop, "Thermomechanical properties of jute/bamboo cellulose composite and its hybrid composites: the effects of treatment and fiber loading," Advances in Materials Science and Engineering, vol. 2017, Article ID 8630749, 10 pages, 2017.

[13] D. Huang, B. Sheng, Y. Shen et al., "An analytical solution for double cantilever beam based on elastic-plastic bilinear cohesive law: analysis for mode I fracture of fibrous composites," Engineering Fracture Mechanics, vol. 193, pp. 66-76, 2018.

[14] Z. Huang, D. Huang, Y. H. Chui et al., "A bi-linear cohesive law-based model for mode II fracture analysis: application to ENF test for unidirectional fibrous composites," Engineering Fracture Mechanics, vol. 213, pp. 131-141, 2019.

[15] J. Long, Thermal and Moisture Stress Analysis of Bamboo Buildings Based on Heat and Mass Transfer Method of Porous Medium, Hunan University, Hunan, China, 2013, in Chinese.

[16] H. Kuwamura, "Creep limit of wood under parallel-to-grain compression," Journal of Structural and Construction Engineering AIJ, vol. 77, no. 681, pp. 1691-1700, 2012, in Japanese.

[17] R. G. Kobbe, "Creep behavior of a wood-polypropylene composite," M.S. thesis, Washington State University, Pullman, WA, USA, 2005.

[18] P. E. Nur Yazdani, E. Johnson, and S. Duwadi, "Creep effect in structural composite lumber for bridge applications," Journal of Bridge Engineering, vol. 9, pp. 87-94, 2004.

[19] J. Tissaoui, Effects of long-term creep on the integrity of modern wood structures, Ph.D. thesis, Virginia Polytechnic Institute and State University, Blacksburg, VA, USA, 1996.

[20] T. Liu, "Creep of wood under a large span of loads in constant and varying environments," Holz als Roh- und Werkstoff, vol. 51, pp. 400-405, 1993.

[21] D. M. Holzer, J. R. Loferski, and D. A. Dillard, "A review of creep in wood: concepts relevant to develop long-term behavior predictions for wood structures," Wood and Fiber Science, vol. 21, pp. 376-392, 1989.

[22] X. Ma, X. Liu, Z. Jiang et al., "Flexural creep behavior of bamboo culm (Phyllostachys pubescens) in its radial direction," Journal of Wood Science, vol. 62, pp. 487-491, 2016.

[23] J. Gattron, K. A. Harries, and Q. Xu, "Creep behavior of bamboo," Construction and Building Materials, vol. 66, pp. 79-88, 2014.

[24] T. Tsubaki and T. Nakano, "Creep behavior of bamboo under various desorption conditions," Holzforschung, vol. 64, pp. 489-493, 2010.

[25] P. Wu, "Experiment and analysis on creep properties of reconsolidated bamboo," Master's thesis, Northeast Forestry University, Harbin, China, 2015.

[26] ASTM D2990-17, Standard Test Methods for Tensile, Compressive, and Flexural Creep and Creep-Rupture of Plastics, ASTM International, West Conshohocken, PA, USA,, 2017.

[27] I. Smith, E. Landis, and M. Gong, Fracture and Fatigue in Wood, John Wiley and Sons Ltd., West Sussex, UK, 2003.

[28] R. G. Kobbe, "Creep behavior of a wood-polypropylene composite," M.S. thesis, Washington State University, Whitman country, Pullman, WA, USA, 2005.

[29] A. Shukla and Y. M. Joshi, "Boltzmann superposition principle for a time-dependent soft material: assessment under creep flow field," Rheologica Acta, vol. 56, pp. 927-940, 2017.

[30] M. M. Hassani, F. K. Wittel, S. Hering et al., "Rheological model for wood," Computer Methods in Applied Mechanics and Engineering, vol. 283, pp. 1032-1060, 2015. 